\title{
High performance leadership in unusually challenging educational circumstances*
}

\author{
Andy Hargreaves ${ }^{a}$, Alma Harris ${ }^{b}$ \\ a Boston College, Lynch School of Education \\ ${ }^{b}$ University of London, Institute of Education
}

\section{Introduction}

We know a lot about the importance of educational leadership. After teachers and teaching, school leadership is the most important determinant of student achievement in the school (Leithwood, Seashore Louis, Anderson, \& Wahlstrom, 2004). School leadership exerts its biggest impact on students indirectly, through how leaders work in galvanizing the efforts and developing the talents of the adults in the school (Hallinger \& Heck, 1998; Supovitz, Sirinides, \& May, 2010). Some leadership experts argue that these effects are products of particular behaviors that have high effect sizes, like participating in professional development with teachers, or providing effective feedback (Robinson, Lloyd, \& Rowe, 2008). Others argue that it is more a matter of style - exercising leadership that is ethical, transformational or distributed, to name just a few of the options (Harris, 2008; Leithwood \& Jantzi, 2000; Spillane \& Camburn, 2006; Starratt, 2004). The impact of effective leaders is especially important when schools operate in challenging circumstances such as high poverty and unemployment (Harris, Chapman, Muijs, Russ, \& Stoll, 2006; Leithwood et al., 2004; Robinson et al., 2008).

We can make judgments about leadership effects by looking at patterns of all leaders or large samples of them; and we can also look at outliers of exceptional, high performance leadership and the factors that characterize

This paper is derived from a large research project co-funded by the UK National College for School Leadership and Specialist Schools and Academies Trust under a grant administered by Boston College and the London Institute of Education. The four case studies on which the empirical material in this paper is drawn were authored in different instances by Michelle De La Rosa, Kathryn Ghent, Alex Gurn, Lori McEwen, and ourselves.

1 Lynch School of Education, Boston College, Campion Hall 109, 140 Commonwealth Avenue, Chestnut Hill, MA 02467, USA; hargrean@bc.edu 
it (Winter, 2003). Especially informative for schools working in very difficult community or demographic circumstances is what high performance leadership looks like when the context appears to be unfavorable or even opposed to securing strong performance results (Borman et al., 2000; Calkins, Guenther, Belfiore, \& Lash, 2007; Chapman, 2008; Harris et al., 2006; Kannapel, Clements, Taylor, \& Hibpshman, 2005; Picucci, Brownson, Kahlert, \& Sobel, 2002).

\section{Leadership and high performance in Estonia}

Estonia is the new international enigma of high performance educational leadership and change. From the first publication of the most widely cited international assessment of student achievement - OECD's Program in International Student Assessment (PISA) - Finland was the top performing country in the world for a long time (OECD, 2014). Even when Singapore surpassed it, Finland still remained the highest performing country outside Asia - until 2012. Then Estonia scored marginally ahead of its neighbor across the Baltic on mathematics and came close to it on reading and science. Estonia is also one of the highest international performers on equity in mathematics: this is despite significantly higher poverty and child poverty levels than Finland (UNICEF ..., 2013). What was this country of just 1.3 million people - bigger than Iceland, but smaller than Norway or Wales - doing to create this acclaimed record of success?

Some attribute Estonia's astonishing advancement to the rapid development of technology and the opening of free markets (helped by lower prices of labor compared to Finland and other Nordic countries). The Economist (How did Estonia ..., 2013) expresses Estonia's technological transformation in dramatic terms:

When Estonia regained its independence in 1991, after the collapse of the Soviet Union, less than half its population had a telephone line and its only independent link to the outside world was a Finnish mobile phone concealed in the foreign minister's garden. Two decades later, it is a world leader in technology.

The Economist points to technological innovation and the thinking to accompany it on online elections, healthcare and tax returns, and the introduction of computer coding skills into kindergarten, for instance (Olson, 2012). Others point to the influence of a Nordic legacy, Puritan spirit, linguistic ties to Finland, and benefits of small scale for implementation 
that allows for rapid feedback from practice to policy. In Estonia, there are few examinations and schools have higher autonomy (Wise Channel, 2014) in a system that is not standardized in the way that many Anglo-American systems are (Hargreaves \& Shirley, 2009; Sahlberg, 2011). At the same time, Estonia is experiencing population decline and net emigration, and wellbeing indicators on UNICEF (2013) rankings are not positive, with Estonia being $23 \mathrm{rd}$ out of 29 developed countries. There is clearly further progress still to be made in nationwide improvement, educationally and socially.

Some of the dramatic changes that have taken place in Estonia have been attributed to the installation of a young political leadership cadre in their early thirties in the new Europe (How did Estonia ..., 2013), uncluttered with old thinking and able to take innovative leaps in social policy development. Alas, Tafel and Tuulik (2007) have analyzed the leadership styles that have characterized Estonia during its transition from „an authoritarian, centralized, totalitarian socialist state, to a democratic country with a free market economy and different attitudes and values" (p. 56). The authors administered to leaders and followers in 63 organizations about their perceptions of leadership behavior, trust and confidence. Their findings are less conclusive but show some mix of traditional authoritarian and more transformational characteristics - in line with James McGregor Burns's (1978) characterization of transformational leadership as providing inspiration, motivation and intellectual stimulation. These combinations amounted to what the authors saw as a mix of or transition between independentthinking leadership styles where leaders informed and consulted followers about decisions they made themselves; and team-player orientations, where decisions were made together.

\section{Investigating unusually high performance leadership}

As Estonia moves through a continuing transition in leadership, as well as in economic, social and educational development, what might it learn from the nature and impact of high performance leadership elsewhere, in other educational systems, and also other sectors?

From 2007 to 2011, we directed a transatlantic team of researchers to study performance beyond expectations in 18 organizations in business, sport and education that was funded by the National College for School Leadership and the Specialist Schools and Academies Trust in England. The nine educational cases of schools and districts were all based in England which was the source of the funding, with the sports and business cases 
being located in England, Ireland, the US, Italy, and Australia. Eventually, to reach a global market of readers, we expanded the study to include high performing educational systems in Finland, Canada, Singapore, London and California, as well as an additional sports case in Canada (Hargreaves, Boyle, \& Harris, 2014). In order to explore issues of unusually high performance in school level leadership, some of the original English case studies and analysis are drawn upon here.

The study explores how organizations in the private and public sector can achieve exceptionally high performances, given their history, size, client base and previous performance. It probes what it means to exceed expectations, the different definitions of performing beyond expectations that exist and also prevail, and the leadership practices within organizations that enable these organizations to excel and outperform others. Our study addressed three key research questions:

- What characteristics make organizations of different types successful and sustainable, far beyond expectations?

- How does sustainability of performance beyond expectations in leadership and change manifest itself in education compared to other sectors?

- What are the implications for schools and school leaders?

Each case was included when there was clear evidence that it met one or more of three clear performance criteria:

- Sequential performance beyond expectations over time in terms of revival or awakening after previous poor performance, or attainment of high success following discouraging early beginnings;

- Comparative performance beyond expectations in relation to high levels of achievement compared to peers;

- Contextual performance beyond expectations as evidenced by strong records of success despite various indicators of relatively limited resource capacity or very challenging circumstances.

All cases also had to meet standards of organizational responsibility or Ethical performance beyond expectations in terms of their treatment of workers, clients and the community.

More than 220 interviews were tape recorded and transcribed. After extensive analysis, original case reports of between 8,000 and 16,000 words each were written for and then approved by the participating organizations according to the ethical protocols of the participating universities. These case reports also drew on collection and analysis of extensive archival, documentary and website data such as mission statements, program information, press articles, performance data, published rankings on various indices, and official histories of as well as other research studies on the organizations in 
question. Except in one geographically remote instance, all case studies were conducted by at least two of the nine research team members to strengthen claims to validity and reliability.

The English education cases comprise two Local Authorities, a strategic partnership of one school improving with the support of another, two secondary schools, three primary schools and a multi-site special education centre. This paper focuses on four of these cases - two primary schools and two secondary schools - and the points they illustrate and generate regarding leadership beyond expectations.

1. Grange Secondary School was in the very centre of the Lancashire mill town of Oldham, at the heart of where some of the worst race riots in British history took place in 2001. From being the town's "flagship” comprehensive school when it was established in 1968 to falling into near failure in 1996, Grange Secondary School then experienced a 10-year trajectory of improvement in examination results and inspectors' judgments, as well as an impressive accumulation of national awards and accolades.

Grange Secondary had to operate in extremely challenging circumstances. Oldham has two areas of multiple deprivation that fall within the most severe $1 \%$ in the country. Grange was in one of these. More than $90 \%$ of the school's students were Asian with the vast majority being Bangladeshi, many from families where little English was spoken and even less was read. Almost two thirds of the students qualified for free school meals.

The school's low point was at the end of 1996 when it scraped a satisfactory grade in its external inspection by the English inspection agency, Ofsted. A new head teacher arrived in 1997 and the current Head took on the job of his deputy. When the Head moved on in 2004, the deputy replaced him until his own retirement in 2008. This period was a decade of remarkable recovery and significant improvement for Grange.

- The proportion of students achieving $5+$ or more GCSE grades $A^{\star}-C$ (secondary school certificates that essentially enabled students to move on to university-bound programs) increased from $15 \%$ in 1999 to $71 \%$ in 2008.

- Between 2000 and 2008, the proportion of students not going on to further education, training or employment fell from $12 \%$ to $3 \%$, less than half the national average of $7 \%$.

- Over a decade, attendance improved from $84 \%$ to $92.5 \%$, close to the national average of $92.7 \%$.

- In terms of the contribution the school made to student progress between ages 11-16 (its contextual value added score), in 2008, Grange was 
positioned in the top $2 \%$ of schools nationally and first among all 16 secondary schools in the local authority.

- Honors and awards included designation as a visual arts specialist school in 2002, becoming the highest performer of 30 such schools nationally in 2005 (and remaining in the top 2 until the school was eventually closed along with other secondary schools in the town in 2010 to be converted into one of a series of academies), and winning a number of significant visual arts prizes such as being the regional Arts and Minds winner in 2004.

Successive inspection reports by England's educational inspection agency Ofsted support this overall trajectory of improvement beyond expectations. Ofsted's 2002 report upgraded the school to the second highest category of "good," which included "areas of excellence" in the school's work. The report noted there had been "very good" improvement since the 1996 inspection. „There has been significant improvement in attendance and good improvement in the quality of the curriculum for Years 10 and 11 . Teaching has significantly improved and standards are rising faster than nationally." By the 2006 report, Grange was still a "good school" at grade 2, but now with „some outstanding features" particularly in terms of supporting and caring for learners and forming partnerships with others. Although GCSE examination results were still "below average," they were "much better than at the time of the previous inspection." This is an impressive improvement record after years of underperformance in the face of profound local educational and social challenges compared to schools in similar circumstances.

2. John Cabot Academy, at the time of our study, was a school serving 1,071 students from 11-19 years old. Originally known as John Cabot City Technology College, the school opened in September 1993 as the last of 15 city technology colleges (CTCs) set up through the 1988 Education Reform Act. John Cabot CTC became John Cabot Academy in 2007. Its sponsors were Rolls-Royce PLC and the University of the West of England.

Examination results at John Cabot had been consistently above the national averages since its first cohort of students sat their GCSE examinations in 1998. Steady improvement in these results from 1998 to 2003 preceded a drop in 2004, although, even then, they remained above the national average. It took 4 years to return to the 2003 level. The Executive Principal, Sir David Carter, who started in April 2004 and stayed until 2014, considered Cabot to have been a "coasting or cruising" school at that point (Stoll \& Fink, 1996). 
I came in April, and by that September, my view was that the job I'd been appointed to was not the job I thought it was. There was a lot of hype around campus about innovation and lots of projects taking place, which was true. But they weren't having impact. And I felt the teaching and learning was very complacent. I felt the leadership wasn't challenging and everybody was happy and cozy in their environment. So, I resolved to take the bull by the horns and see whether I could bring Cabot to be an outstanding school.

Following Carter's arrival, GCSE results steadily improved. The school's 2009 Ofsted report ranked it as outstanding (the highest grade) in almost all categories. The meaning of performing above expectations within John Cabot also reached beyond a definition of academic scores and standards to include a focus on the development of the whole child, continual improvement of teaching and learning and commitment to curriculum innovation as is evidenced in the Cabot Competency Curriculum the school developed with others in the Cabot Federation that is now a collection of twelve schools led by Cabot under a single Learning Federation.

3. Limeside Primary School, like Grange, is also in Oldham, and is set in an area of significant social and economic deprivation that has had problems with poor social housing, racism, high unemployment and low aspirations. A high number of students are eligible for free school meals and, at the time we studied the school, more than a quarter of the students had learning difficulties and/or disabilities. The majority of the school's families lived on the Limeside housing estate in rented accommodation.

In 1999, the school was in a dilapidated building and had reached a low point with appalling results, apparently uncontrollable children, overwhelmed teachers and a poor community reputation. A series of very critical inspections resulted in the school being placed in Special Measures in 2000.

In the following decade, Limeside experienced a steady and sustained improvement. Test scores were well above the national average by 2007 when the Ofsted inspection report judged the school to be outstanding.

The former Head of Limeside was responsible for getting the school out of Special Measures by 2002. A large number of teachers left the school and experienced staff was brought in to support improvements in teaching and learning. A new behavioral strategy was introduced, focusing on positive reinforcement. The succeeding Head (previously the deputy) made further improvements to the school building, restructured roles, introduced sweeping changes to the curriculum, refocused staff and students, and 
connected the school more strongly to its community. From the standpoint of the children, performing beyond expectations also meant that from being labeled as badly behaved, low achieving and having low aspirations, they became transformed into children who loved learning and coming to school.

Following Ofsetd designation as an outstanding school, Limeside converted into an academy, becoming Oasis Limeside Academy in 2011. It is now a National Support School for the training of teachers.

4. Mills Hill is a large primary school also in the centre of Oldham. Mills Hill is an example of school improvement under a new head working almost exclusively with the existing staff base. When the Head at the time of our study began in the spring of 2004, he felt the school would need to critically reassess the way it operated in terms of teaching and learning. Change was triggered by a local authority inspection that he initiated which judged Mills Hill to be a school that was causing concern.

Capitalizing on the apprehension resulting from the critical evaluation, in 2004-2005, the Head and staff undertook a process of pedagogical transformation that was focused primarily on implementing the principles of cooperative learning. Results picked up again and attained performance levels beyond expectations.

In 2008, a federation was formed between Mills Hill and Medlock Valley Schools with a shared leadership structure and unchanged teaching staff. Medlock Valley had performed below its base targets for student achievement for 8 years. In July 2009, Medlock Valley's test results were above its base targets for the first time. Mills Hill was judged to be an outstanding school by Ofsted; which was confirmed by a routine interim assessment three years later.

\section{The journey of high performance leadership}

For some, leadership is a set of competences: a list of capabilities that can be listed and checked on development programs and standard frameworks that are linked to qualifications, licensure and performance evaluations. Others see that the coherence of leadership concerns how these competences hang together in a meaningful way. Leadership here is about how dots are joined up to create system coherence as much as it is about the existence of the dots themselves (Fullan, 2005). Leadership is also about influence, movement, and change: it is about how the dots flow on a journey of development and transformation from point in time to another. This raises the basic idea that in times of change, leadership is also a narrative, a quest or a journey. 
The remainder of this paper examines the improvement journey of the four schools featured in this analysis by drawing upon a four- fold framework, derived directly from the study. These four phases comprise:

- Dreaming with determination including having a dream of a significantly more desirable future, confronting and overcoming one's fears, challenging forces of resistance, and pursuing the dream with relentless determination.

- Taking Innovative Pathways including identifying opportunities that others have missed and turning one's greatest weaknesses into significant triumphs.

- Building Collaboration and Community involving establishing creative teams, and engaging in friendly rivalry.

- Securing Success and Sustainability by making a coherent connection between short-term improvements and long standing success so that resources are not squandered and people do not become burned out.

\section{Dreaming with determination}

Our study showed that leaders who perform above expectations are able to make clear, compelling and challenging connections between current difficulties or unpromising starting points and a distant dream. This better future reminds people them where they came from, what they must recover, and how this is connected to what lies ahead. All our school cases show that this journey is made in the face of and also, ironically energized, by an apparently insurmountable challenge or opposing force that includes the haunting specter of failure in the past and the daunting prospect or fear of failure in the future.

Organizations that perform beyond expectations aspire to and articulate an improbable, collectively held fantasy or dream that is bolder and more challenging than a target, a ranking, a plan or even a vision.

At Limeside Primary School, once a stable staff base had been established, effort was invested in creating a shared school vision. The whole staff attended a training day out of school where they wrote down what they would like to see in their dream school. All staff who was interviewed talked about how important this was for them, the school and the children. The Assistant Head depicted how:

"It's like walking through this place and seeing and hearing everything you're going to do, it would be happening in your dream and in many ways that has really begun to happen because we talked about it all the time, we use it all the time, constantly referred to it, but it's 
now your ideas and your vision of what that vision will look like. The daring to take risks and I'm talking about children taking risks but also about the staff and the school as a whole taking risks and being creative and having new ideas and saying, „Right, we'll go with them.”'

Leaders who perform beyond expectations are determined to succeed whatever the odds, but not simply to be „top," „best,” „world class” or Number One. Rather, they have an inspiring and definable destination to reach for - a compelling dream rather than a core purpose, still less a numerical indicator of superiority. In John Cabot Academy, the Head had a dream to regenerate the local area by his school and other schools working together and became the Executive Head of several schools in a Federation that jointly raises performance for young people and increases the aspirations of the community.

Pursuing dreams isn't just a matter of fantasy or speculation. It is more than a hope or a wish. Organizations that perform above expectations, rather, often have to confront failure, derision and even the prospect of extinction in a way that galvanizes their commitment to change. An improbable dream begets an apparently impossible challenge. Most of our leaders at some time had faced a seemingly insurmountable obstacle. Many had looked failure and apparent disaster in the face.

In Mills Hill Primary School, at the start of the academic year 2001-2002, the school witnessed the abrupt departure of its then long-standing and respected Head, putting it through a period of significant leadership instability. With weak succession planning, Mills Hill experienced a void in strong headship and a significant dip in its performance. The fear was that this dip would continue and the school would continue to spiral downwards. There was a great sense of apprehension that the school was in a downward trajectory that could not be halted.

Leading people through profound change does not occur without fear of failure, threat or the future. At some moment, many leaders experience self-doubt as they stare defeat in the face. What defines leaders who perform beyond expectations is not the absence of fear but how they deal with their fear and with the fears of those around them. These leaders fight to overcome or circumvent obstacles, instead of taking flight to avoid them.

In 1996, Grange Secondary School only just passed its Ofsted inspection. Graeme Hollinshead, who would go on to become the school's Head, was frustrated with and despondent about the school. In his 
heart of hearts, he knew that it hadn't deserved to pass. And if four particular teachers had not been absent that week, it might not have done so. Graeme took two weeks off school, sick, then went to discuss his troubling feelings with a hospital consultant. The consultant listened patiently and then delivered his expert medical advice. This was Northern England, not Southern California, so his feedback was bracing and brutally direct. „He just advised me to get back in and sort it out,” said Graeme, „which I did!”

At Mills Hill, the Head initiated a Local Authority inspection and the school was identified as a "school causing concern," an outcome that created a stir in the school and even a sense of fear among staff. After having proved his ability to improve efficiencies in the school's management and administration, the Head capitalized on apprehension from the negative evaluation, to build consensus among staff and other key stakeholders that the school was in need of real change. This was the start of the fight back.

Leaders who perform beyond expectations deliberately seek out acute challenges and exceptional crises. Leadership beyond expectations is not about fearlessness. It is about facing one's fears in pursuit of one's dream and doing what has to be done all the same. It is about fighting back, fending off superiors, beating untrodden paths, „sorting it out” and insisting expectations are met.

For leaders who perform beyond expectations, crises are catalysts for change. At Grange Secondary School, the catalyst was a barely satisfactory inspection report. At Mills Hill Primary School, the new head teacher initiated an external Local Authority review when he felt the school was not achieving its potential. Leaders who perform beyond expectations capitalize on crises to galvanize the motivation and actions of people in the organization to pursue their shared dream with relentless determination.

Fearlessness and determination in pursuing a dream are manifest not only in momentous acts of courage in response to crises and challenges, but also in the continuous grind of relentless commitment and indefatigable effort. Leaders are called upon to dig deep, to find something within themselves they may never have realized they had. They have to have fortitude. Persistence, perseverance, relentless hard work and driving oneself and others forward are essential, at some point, to almost all leadership beyond expectations. 
At John Cabot, the principal stood firm for the school to become an Academy despite local resistance and a political backlash. He believed that Academy status would benefit the school and was convinced this was the right decision. John Cabot became one of the first Academies to open in the southwest of England and has been instrumental in supporting the development of several other academies in the area that are collectively contributing to community regeneration.

Acting against precedent, scepticism and resistance requires courage, fortitude and great reserves of self-belief. Leaders who have setbacks and disappointments know how to get over them. Graeme Hollinshead and Colin Bell at Grange Secondary School personally rounded up truants from the local park to begin to turn around the attendance record to show the rest of the staff that change was possible. Their dream for Grange and its future was matched by complete and utter determination.

\section{Taking innovative pathways}

Organizations that perform above expectations forge clear yet creative pathways for moving ahead that others have overlooked or rejected. Leaders of organizations that perform above expectations are prepared to go against the mainstream, and to move ahead not by going with the flow but against or around it. These leaders are courageous, creative and counter-intuitive. They welcome argument, disagreement and resistance. Improbability and opposition are their energizing allies. In times of crisis, scarcity or threat, they expand when others contract, challenge their superiors when they have to, and make the first move instead of following the rest.

Strong armies win wars by copying the strategies of their rivals and overpowering the opposition; weak armies win wars by adopting unconventional strategies that their opponents do not expect (Arreguin-Toft, 2001). Leaders who perform beyond expectations do not merely want to be as good as the best by emulating their existing strategies for success. They aim to be better than the best and the rest by taking counter-intuitive steps that often seem to confound common practice and even common sense. This enables them not just to catch up to but also to move aside from and ahead of the pack.

Grange Secondary School designed a creative curriculum that fits the students instead of adopting the customary strategy of spending more time on standardization and drill in the prescribed curriculum to drive performance numbers up. Indeed, all the schools and local authorities in our study kept on raising performances not by investing 
in quick-fix tactics to raise test scores of the kind that some peers had engaged in, but by developing an interdisciplinary curriculum, cooperative learning strategies and other pedagogical innovations to produce authentic success. John Cabot's Competency Curriculum, developed to improve the Year 7 curriculum, does not follow the National Curriculum. „We continue to work with the Year $7 \mathrm{~s}$ in a competency-based approach rather than saying we'll fit the Year 7 National Curriculum to these year 7s," they said. Mills Hill Primary School based its entire curriculum on the cooperative learning strategies of Spencer Kagan, and flew its staff across the Atlantic to undertake common training in the Kagan approach.

Limeside Primary School did not teach the traditional National Curriculum. The Deputy recalled how the curriculum that was „provided for these children with such huge problems wasn't suitable because they were trying to make the children fit the curriculum. But if you start from where the child is, what they want to find out about, what they want to learn, and you start personalizing the curriculum and you make the curriculum fit the child, then you change things". At Limeside, personalization didn't just mean customization or individualization of an existing curriculum - speeding it up or slowing it down. Personalization was about connecting learning to children's lives and the ways they learn best. Children were taught to think about how they learn and what makes a good learner. Learning was celebrated by the use of the 'wizard learners' reward system. The school put a toy wizard up in the foyer and he became the model learner: a symbol of what learning is and how children could become a wizard learner. Wizard hats and cloaks were purchased and anybody who had shown they were a wizard learner was dressed up in assembly to receive their certificate. There had been little or no celebration of children's achievements before the school went into Special Measures. The wizard learner was one of the many ways this has been turned around.

In times of crises, leaders who perform beyond expectations often do the exact opposite of what might be expected or anticipated. They are unconventional and counter-intuitive thinkers who know how to be imaginative and resourceful in adverse and volatile conditions. They tend to be relentlessly optimistic even in the face of evidence that demonstrates the extent of the challenge or the unlikelihood of success. Like the innovators in Clayton Christensen's (2013) The innovator's dilemma, they are often rejected by the 
mainstream at first only to find that their ideas redefine the mainstream later on.

\section{Building collaboration and community}

Performing beyond expectations involves everyone in the organization. It depends on engaging a talented team in which risk and creativity are valued, honest mistakes are acknowledged and tolerated and members participate and "play” in interchangeable roles and positions. In organizations that exceed expectations, people have a deep faith in and faithfulness to their colleagues, the people they serve, and a higher purpose greater than any one of them. Last, organizations that perform beyond expectations relate to their peers and even their opponents through creative and counter-intuitive combinations of competition and collaboration where success partly rests on the success of others and a sense of social justice inspires service to neighbors who are less fortunate.

Leaders in organizations that perform above expectations have a deep faith in and faithfulness to their colleagues, the people they serve, and a higher purpose greater than any one of them. These leaders keep people with them. Many of our organizations excelled and even turned themselves around with long-standing staff members who had worked there for decades. High performing leaders generate fierce loyalty through their ability to work hard and long to achieve what is wanted and to engage others in their quest. This loyalty helps them to make quick and difficult decisions without losing support. It is about knowing people, committing to them and caring for their lives. Leaders who perform beyond expectations actively build relationships and engender high trust and loyalty among colleagues in order to take significant risks. They know their people and do not impose expectations from afar. At Limeside Primary School, the head teacher remarked, „The parents come and say to me, „We used to feel embarrassed about saying that we were from Limeside and now we are very, very proud'"'

Organizations that perform beyond expectations and their leaders care about, engage with and support the communities that have importance for them. Sometimes this is the community they serve and in which they are physically located.

The Oldham race riots of 2001 had a significant impact on the ways in which Mills Hill has reached out to the surrounding community. The disturbances forced staff to consider how they might improve connections with the growing ethnic minority community. Though 
Mills Hill did not have high numbers of cultural minority students, the school chose to seek out ways to create links outside the insular walls of the school with global communities. In addition to this international work, Mills Hill maintained a partnership with another local school that is majority Bangladeshi and Pakistani through the 'Oldham Linking' project. For more than three-and-a-half years, they ran joint activities to build cross-cultural understanding.

Mills Hill worked with its community and also as a community. All staff collaborated in teams. Team meetings focused on a variety of topics, such as understanding and using student data, discussing observations of students, sharing how particular lessons worked, talking about research articles, and brainstorming ways to improve practices. One key purpose of teaching teams had been the introduction of regular peer evaluations, which were instituted to enhance teaching and learning, and to induct newer teachers. A teaching assistant felt that ,there's always someone you can go to ... Everybody is approachable. Nobody turns you away."

It is not just teams and teamwork that keep organizations that perform beyond expectations moving forward; it is the vibrant nature of the teamwork itself. Organizations that perform beyond expectations have cultures of creativity and risk-taking. They allow and encourage workers to have freedom and flexibility to innovate and play. These changes in culture and creativity are facilitated by structural reorganizations that emphasize interchangeability, rotation and cross-cutting of roles and positions.

At John Cabot Academy, an essential component of performing beyond expectations was an environment of innovation and risktaking. The 2007 Ofsted inspection report commented that, „Innovative developments are continuing to raise standards" The 2009 Ofsted report referred to the school's competency-based curriculum as "an example of an innovation that has had an excellent impact on students' attainment and progress". Innovative learning calls for innovative teaching. Cabot's staff members were given considerable autonomy to engage in risk-taking, innovation, and creativity for the sake of enhancing the school's performance. Innovations varied in their success and impact and were modified or discontinued as needed. The Director of the Cabot Learning Federation commented that at John Cabot, it is about ,innovation with impact” and about „a strong leadership team, not just a person." Some people viewed this 
environment of risk-taking as being an important motivator for taking or remaining in their jobs at the school.

Cabot's culture of innovation kept it moving forward while attracting the best people to it and keeping them together. Grange Secondary School engaged its Bangladeshi students and renewed its staff by emphasizing the arts and creativity - with the effect that many senior leadership team members were recruited from art and design subjects that, they felt, equipped them with the „big picture thinking” that made them better leaders.

Collaboration and teamwork also extended to working with other schools, some of which were potential competitors. Mills Hill formed a federation with a neighboring school that had a very different ethno-cultural composition from its own. Grange willingly and openly shared its idea and insights with schools from all over the country. Cabot led a federation of several schools in the region that it assisted through its own leadership. In unusually high performance leadership competition is not win-lose but win-win where everyone helps each other for mutual advantage and also to achieve a greater good.

\section{Fusing success with sustainability}

Leaders in organizations that perform above expectations raise and rally the organization and its performance by leading from the front by example when they have to; lifting up everyone around them morally, emotionally and spiritually at every opportunity; and distributing leadership beyond them to ensure improvement is sustainable and not overly dependent on themselves.

Leadership beyond expectations is not just a choice between styles, or a bundle of skills and competencies. Leadership beyond expectations is a fusion and flow of qualities, characteristics and behaviors - some of them apparent opposites. This fusion arises within individuals as a matter of personal integration and integrity, it emerges throughout communities as an achievement of collective capability, and it evolves over time as a means of securing progression and sustainability. The nature of fusion leadership is illustrated in one of the present examples of performing beyond expectations - Grange Secondary School.

The low point for Grange Secondary School was when it almost failed its external inspection in 1996. Together, the Head and Deputy started to lead by example. They set down firm foundations and short-term success markers for improvement by calming down student behavior 
with a positive discipline strategy. „Behaviour was poor, morale was poor, and attendance was $84 \%$. Everything needed improving." At first, Bell and Hollinshead showed courage and fortitude by leading boldly and resolutely from the front. They took some of the worst behaved students in the school into town and out to theme parks when they behaved well, even though their staff thought they were crazy. "We used to do things like getting in our cars and rounding up the kids from the park. There was nothing we wouldn't do. We'd go knocking on doors saying, „Why aren't you in school?” The result was a climate characterised by „calmness on the corridors," collective staff responsibility to care for children, willingness to listen to them and a capacity to understand the students and „where they were coming from."'

Most leaders who perform beyond expectations find ways to lift people's spirits and raise their hopes. Until the mid 1990s, Grange had been managed by "nice" people but ,there was no initiative at all” The Senior Leadership Team had isolated itself on "the top corridor" where one of them „even used to crochet most of the day." The atmosphere "felt lax." One teacher recalled how senior leaders "never set foot in my classroom.” Then, ,all of sudden we got a Deputy Head, Colin Bell, who's got vision, who's got experience of other things.” „He had been a Deputy Head of a very challenging school in Manchester and was rather streetwise as well - very unlike the two heads that we had previously." Bell was "not tied to the social history of the school and was like a breath of fresh air." Hollinshead, Bell's deputy and then successor, recalled how Bell „brought tremendous charisma. He was inspirational. He certainly got people doing things.” One of his strengths was that he was a „very, very good people person." One teacher, now a senior leader, vividly remembers her very first contact with the school as a supply teacher, when Bell was in charge of supply teacher appointments and coverage.

„He was asking me a lot of questions and explaining about this new senior leadership team and how they were trying to create a team of people who would come in on supply. He asked would I be willing to come in and do different subjects, etc., etc. I said that I would. But at the time I was thinking, „Why are you asking me all this because I'm only coming in for one day?" Anyway, I did my day. And there was just something about the place that made you feel welcome. Maybe it was the fact that the guy took the time to sit down and have the conversation. Now people who come here on supply say there is definitely 
an ethos of being welcome in the school, which I think is about valuing people from a supply teacher coming in for one day, to the cleaning staff, the kitchen staff and the pupils. I think everybody feels that they belong to the school and that their contribution matters."

When he became Head, Bell met with the governing body responsible for the school and set out his vision: He had plans and brought them to the governing body, and at a time when the percentage of A-C grades was minimal, he was able to look to the future and say, „Well in two or three years time, this is what I want and to get that vision across to everybody and working for it".

Courageous leadership from the front had been followed by inspiring and visionary leadership that motivated everyone else. This was amplified by the innovative leadership that redesigned the curriculum around visual and creative arts to suit the predominantly Bangladeshi learners, and this in turn attracted resources for the school to become a leading Visual Arts College. When the promise of better times becomes evident in small increments of concrete improvement such as these, this can generate upward spirals of further hope and increased confidence that even greater improvements are possible. „You went from being a teacher at the school that was the worst performing to someone who was working in a reasonable work environment with good facilities, with students who were improving and this was being recognized. I think all that has a very positive impact on you and encourages you to keep on going."

Eventually, the leadership responsibility for improvement became widely distributed (Harris, 2008; Spillane \& Camburn, 2006). Hollinshead tried "all the time to distribute the leadership" and develop teamwork. The team comprised everyone - teachers, learning mentors, teaching assistants and support staff. Union representatives were always involved early when new directions were being taken. The business manager was complimentary about how everyone would "rally round" when someone had a problem, how Hollinshead knew how to delegate, and how he „lets you get on with it.” Through building a culture of trust, warmth and loyalty, distributed leadership at Grange turned into collective responsibility. Hollinshead observed that "the Head can't do everything. He's got to have key people in key positions that are accountable no matter what they do." With this collective, distributed responsibility, the Head did not always have to be in school, but could be outside advocating for it, and gathering other ideas and insights that could support it. So Hollinshead "goes off all 
over the place." Gilly McMullen, his successor, pointed out that, „He's out of school all the time" but "it's just business as normal. When he's not here you would not notice."

Grange's leadership was not only successful and spread out across the community. It was also sustainable over time as it built long-term recruitment capacity and also established confidence-building shortterm successes (Hargreaves \& Fink, 2006).

In organizations that perform above expectations, the pace of change is as important as its flow. Organizations that perform beyond expectations don't try to expand as quickly as possible and take off too fast. They are built on sustainable growth. They show practical and prudent attention to growth rates that do not compromise the future by improving or expanding too quickly in the present, at the cost of imported "stars" or pushing staff to the point of burnout. They pay attention to the short-term and long-term together without sacrificing one to the other.

At Limeside Primary School, it took time to secure sustainable growth. There were no quick fixes. The behavior of the children was a lot more challenging than anywhere the incoming seconded staff had worked before. It took 2 to 3 years for the expectations to filter through to get to the standard they are now. A nurture class took disruptive children out of the classroom and gave them one-to-one support. Misbehaving children in class could be removed and sent to an on-call teacher for ten minutes until they calmed down. A playground „bully system” was set up and a wildlife garden established to make the environment less stark. Children were able to participate in a newly created school council. The head teacher established philosophy sessions and meditation periods to build mutual respect and settle children into the day. Staff spoke of „a bombardment of high expectations," of expecting the best from the children all the time. This included recognizing every little achievement and making sure it was rewarded and telling the children, „We're so proud of you for what you've done," and giving the message, ,You're worth so much more than you think you're worth." A lot of the change was about building self-esteem and children celebrating their achievements. Once all those systems were put into place, the children became proud of themselves and wanted to achieve. In the words of the Assessment Coordinator, „It's almost like brainwashing them into believing in themselves because it's just constant, constant, constant. Deep down, they're just being built up 
all the time. So over a period of time they believe in themselves." All of this is urgent, persistent and effective, but none of the results of all this work happen overnight.

None of our organizations featured here and in the wider study are nine-day wonders. All emphasize the importance of sustainable growth. And all the schools in this study raised achievement scores not by fabricating quick lifts by teaching to the test or working only on examination borderline cases, but by authentically transforming teaching and learning and the depth of student engagement.

The schools in our study have also had strong records in growing leaders from within so that teamwork brings tangible rewards as well as symbolic ones. In organizations that perform beyond expectations, people do not merely cooperate to complete tasks as teams but live and grow together as entire communities.

\section{Conclusion}

Leadership beyond expectations cannot be timelessly categorized in a single style, described by one adjective, or captured in a long list of competencies. The essence of leadership beyond expectations, rather, is its capacity to shift, flex and flow over time, as the organization evolves and the circumstances require. Leadership beyond expectations is a story narrated over time, rather than a style or a checklist. It is to be found in the capacity to fuse many leadership styles and components together into an integrated and self-assured whole that can lift people up, bring them together, and connect them to something greater than themselves in the future to serve a common good (Daft \& Lengel, 2000).

What is the next step in Estonia's leadership and change trajectory? Will the leadership strategies that brought it to this point be effective in taking the nation's educational system to the next level? The system has been effective and indeed a world leader in educational achievement in mathematics. What will it now need to combat poverty and promote wellbeing? Estonian leadership, at least a few years ago, has been characterized as somewhere between informative and more fully collaborative. Can Estonian leaders distribute leadership effectively in the future and sustain it from one generation to the next over time through its own leadership development plans? At the end of the day, it is one thing to perform above expectations. It is altogether another thing to keep performing above expectations. 


\section{References}

Alas, R., Tafel, K., \& Tuulik, K. (2007). Leadership style during transition in society: Case of Estonia. Problems and Perspectives in Management, 5(1), 50-60.

Arreguin-Toft, I. (2001). How the weak win wars: A theory of asymmetric conflict. International Security, 26(1), 93-128. doi: http://dx.doi.org/10.1162/016228801753212868

Borman, G. D., Rachuba, L., Datnow, A., Alberg, M., MacIver, M., Stringfield, S., \& Ross, S. (2000). Four models of school improvement. Baltimore: Johns Hopkins University.

Burns, J. M. (1978). Leadership. New York: Harper \& Row.

Calkins, A., Guenther, W., Belfiore, G., \& Lash, D. (2007). The turnaround challenge: Why America's best opportunity to dramatically improve student achievement lies in our worst-performing schools. Mass Insight Education (NJ1). Retrieved from http://www.oxydiane.net/IMG/pdf_TheTurnaroundChallenge_MainReport.pdf.

Chapman, C. (2008). Towards a framework for school-to-school networking in challenging circumstances. Educational Research, 50(4), 403-420. doi: http://dx.doi.org/10.1080/00131880802499894

Christensen, C. M. (2013). The innovator's dilemma: When new technologies cause great firms to fail. Boston: Harvard Business Review Press.

Daft, R. L., \& Lengel, R. H. (2000). Fusion leadership: Unlocking the subtle forces that change people and organizations. San Francisco: Berrett-Koehler Publishers.

Fullan, M. (2005). Leadership \& sustainability: System thinkers in action. Thousand Oaks: Corwin Press.

Hallinger, P., \& Heck, R. H. (1998). Exploring the principal's contribution to school effectiveness: 1980-1995. School Effectiveness and School Improvement, 9(2), 157191. doi: http://dx.doi.org/10.1080/0924345980090203

Hargreaves, A., Boyle, A., \& Harris, A. (2014). Uplifting leadership: How organizations, teams, and communities raise performance. San Francisco: Jossey-Bass.

Hargreaves, A., \& Fink, D. (2006). Sustainable leadership. San Francisco: Jossey-Bass.

Hargreaves, A., \& Shirley, D. (2009). The fourth way: The inspiring future for educational change. Thousand Oaks: Corwin Press.

Harris, A. (2008). Distributed school leadership: Developing tomorrow's leaders. London: Routledge.

Harris, A., Chapman, C., Muijs, D., Russ, J., \& Stoll, L. (2006). Improving schools in challenging contexts: Exploring the possible. School Effectiveness and School Improvement, 17(4), 409-424. doi: http://dx.doi.org/10.1080/09243450600743483

How did Estonia become a leader in technology? (2013, July). The Economist explains. Retrieved from http://www.economist.com/blogs/economist-explains/2013/07/ economist-explains-21.

Kannapel, P. J., Clements, S. K., Taylor, D., \& Hibpshman, T. (2005). Inside the black box of high-performing high-poverty schools. A report of the Prichard Committee for Academic Excellence. Retrieved from http://www.prichardcommittee.org/wp-content/ uploads/2013/02/Inside-the-Black-Box.pdf.

Leithwood, K., \& Jantzi, D. (2000). The effects of different sources of leadership on student engagement in school. In K. A. Riley \& K. Seashore Louis (Eds.), Leadership for change and school reform: International perspectives (pp. 50-66). Oxon, New York: RoutledgeFalmer. 
Leithwood, K., Seashore Louis, K., Anderson, S., \& Wahlstrom, K. (2004). Review of research: How leadership influences student learning. The Wallace Foundation. Retrieved from http://www.wallacefoundation.org/knowledge-center/school-leadership/key-research/Documents/How-Leadership-Influences-Student-Learning.pdf.

OECD (2014). PISA 2012 results: What students know and can do: Student performance in mathematics, reading and science (Vol. 1, Rev. ed.). OECD Publishing. Retrieved from http://www.oecd.org/pisa/keyfindings/pisa-2012-results-volume-I.pdf.

Olson, P. (2012). Why Estonia has started teaching its first-graders to code. Retrieved from http://www.forbes.com/sites/parmyolson/2012/09/06/why-estonia-hasstarted-teaching-its-first-graders-to-code/.

Picucci, A. C., Brownson, A., Kahlert, R., \& Sobel, A. (2002). Driven to succeed: Highperforming, high-poverty, turnaround middle schools. Volume I: Cross-case analysis of high-performing, high-poverty, turnaround middle schools. Austin: The University of Texas at Austin.

Robinson, V. M., Lloyd, C. A., \& Rowe, K. J. (2008). The impact of leadership on student outcomes: An analysis of the differential effects of leadership types. Educational Administration Quarterly, 44(5), 635-674. doi: http://dx.doi.org/10.1177/0013161X08321509

Sahlberg, P. (2011). Finnish lessons: What can the world learn from educational change in Finland? New York: Teachers College Press.

Spillane, J. P., \& Camburn, E. (2006). The practice of leading and managing: The distribution of responsibility for leadership and management in the schoolhouse. Paper prepared for presentation at the Annual Meeting of the American Educational Research Association, San Francisco, April 7-11, 2006.

Starratt, R. J. (2004). Ethical leadership (Vol. 8). San Francisco: Jossey-Bass.

Stoll, L., \& Fink, D. (1996). Changing our schools. Buckingham: Open University Press.

Supovitz, J. A., Sirinides, P., \& May, H. (2010). How principals and peers influence teaching and learning. Educational Administration Quarterly, 46(1), 31-56. doi: http://dx.doi.org/10.1177/1094670509353043

UNICEF Office of Research (2013). Child well-being in rich countries: A comparative overview. Innocenti Report Card 11. Florence: UNICEF Office of Research.

Winter, S. G. (2003). Understanding dynamic capabilities. Strategic Management Journal, 24(10), 991-995.

Wise Channel (2014). PISA rankings: Estonia on the upgrade [video file]. Available from http://youtu.be/9_uHF2H0NyI. 